\title{
Experimental and Quantum Chemical Studies on Ethanol Extract of Phyllanthus amarus (EEPA) as a Green Corrosion Inhibitor for Aluminum in $1 \mathrm{M} \mathrm{HCl}$
}

\author{
Eddy Okon Nnabuk ${ }^{a, *}$ and Femi Awe ${ }^{b}$ \\ ${ }^{a}$ Department of Chemistry, Federal University, Lokoja, Kogi State, Nigeria \\ ${ }^{b}$ Department of Chemistry, Federal University, Dutsinma, Katsina State, Nigeria
}

Received Februry 3, 2017; accepted November 20, 2017

\begin{abstract}
This work investigates the effectiveness of the ethanol extract of Phyllanthus amarus (EEPA) as a possible green corrosion inhibitor for aluminum in a $\mathrm{HCl}$ solution, using weight loss, linear and potentiodynamic polarization methods, in order to evaluate the inhibition efficiencies of the plant extract, at various concentrations. Scanning electron microscopy and Fourier transformed infra red spectroscopy were used to study the surface morphology and engagement of functional groups in the corrosion inhibition process. The results obtained at $303 \mathrm{~K}$ from weight loss, linear polarization resistance and potentiodynamic polarization methods recorded an inhibition efficiency that ranged from 56.65 to $69.17,65.00$ to 93.93 and from 51.38 to $79.96 \%$, respectively. Generally, the inhibition efficiency increased with higher concentrations, but decreased with a rise in temperature. The potentiodynamic study revealed that EEPA acted as a mixed type inhibitor, and formed an insoluble film, which protected the metal against corrosion. Examination of micrographs in the inhibitor presence and absence also confirmed the role of the protective film in blocking the corrosion active sites on the metal surface. Spectra analysis obtained from Fourier transformed infra-red study indicated that EEPA was adsorbed onto the aluminum surface via $\mathrm{C}=\mathrm{O}$ and $\mathrm{OH}$ functional groups. The inhibitor adsorption was spontaneous, exothermic, and supported the physical adsorption mechanism. Calculated quantum chemical parameters for EEPA constituents revealed that Phyllanthusin $D$ is the most active corrosion inhibitor in the compound. HOMO and LUMO diagrams of Phyllanthusin D supported the findings from FTIR analysis.
\end{abstract}

Keywords: Corrosion, aluminium, inhibition and Phyllanthus amarus.

\section{Introduction}

Corrosion is an electrochemical process that degrades and converts metals to their natural state. The effect of such destruction is enormous, because of the high cost required for the replacement of damaged metallic components.

\footnotetext{
* Corresponding author. E-mail address: nabukeddy@yahoo.com
} 
Aluminum is one of the most industrial valuable metals, therefore, protecting it against corrosion damage is necessary. Although several protection/control measures against corrosion are available, the use of inhibitors is one of the best and acceptable options[1].

Corrosion inhibitors are substances that retard the metal corrosion rate, when added in a minute concentration [2]. Trends in research, development and application of corrosion inhibitors in industries have moved from inorganic inhibitors to organic inhibitors and to green inhibitors in recent times [3]. Extracts of plants are widely accepted as components that have promising features in the corrosion industries [4]. This is because most of them are cheap, easily available, biodegradable and eco-friendly [5]. The present study is designed to investagate the corrosion inhibition properties of the ethanol extract of Phyllanthus amarus (EEPA) for aluminium in $1 \mathrm{M} \mathrm{HCl}$.

Phyllanthus amarus is regarded as a weed, although some of its medicinal values have been harnessed in recent times [6]. Success has been widely recorded on the potency of this plant extract as a corrosion inhibitor for some metals. For example, Okafor et al. [7] found that seeds, leaves and a combination of seeds and leaves extracts of $P$. amarus are good adsorption corrosion inhibitors for aluminum in $\mathrm{HCl}$ and $\mathrm{H}_{2} \mathrm{SO}_{4}$ solutions. The extracts inhibited the corrosion of mild steel through the mechanism of chemical adsorption. Their adsorption best fitted the Temkin adsorption model. Sangeetha et al. [8] also found that a combination of $P$. amarus extract with $\mathrm{Zn}^{2+}$ system in the ratio of $2 \mathrm{~mL}: 25 \mathrm{ppm}$ yielded an inhibition efficiency of $98 \%$ for carbon steel corrosion, in an aqeuous solution containing $60 \mathrm{ppm}$ of chloride. Polarization data revealed that the extract acted as a mixed type inhibitor, while AC impedance data indicated the formation of a protective film that formed a barrier against further corrosion attack. However, in their study, they did not provide data that could enable the mechanism of adsorption and the best fitted adsorption isotherms to be proposed. Pasupathy et al. [9] also investigated the corrosion inhibition efficiency of the leaves extract of $P$. amarus for zinc in $0.5 \mathrm{~N} \mathrm{H}_{2} \mathrm{SO}_{4}$, and found that it is a good adsorption inhibitor. Although the authors did not investigate the inhibitor adsorption mechanism, they found that the extract adsorption obeyed Temkin adsorption model. Sribharahy et al. [10] found that the extract of $P$. amarus inhibited mild steel corrosion in sea water, with maximum inhibition efficiency approaching $98 \%$. The extract, however, acted as an anodic inhibitor for mild steel in sea water. Olusegun and Otaigbe [11] studied the corrosion inhibition potential of the extract of $P$. amarus, and found that it was a good adsorption inhibitor for aluminum corrosion in an alkaline solution. Maximum inhibition efficiency of $76 \%$ was recorded, and the inhibitor adsorption characteristics responded best to the Langmuir adsorption model. Although the authors did not investigate the effect of temperature, and were unable to propose the extract adsorption mechanism onto the metal surface, a zero order kinetics was proposed. Eddy [6] used the ethanol extract of $P$. amarus to inhibit mild steel corrosion in $\mathrm{a}_{2} \mathrm{SO}_{4}$ solution, and found that it acted as an adsorption inhibitor. However, he proposed a physisorption mechanism, of which adsorption characteristics fitted the Langmuir adsorption model. 
The above review indicates that the adsorption mode, corrosion inhibition mechanism and adsorption characteristics of $P$. amarus vary with the type of metal, aggressive medium and extraction mode. To the best of our knowledge, literature on the use of $P$. amarus as an inhibitor for aluminum in a $\mathrm{HCl}$ solution is scanty. The present research is aimed at using EEPA to inhibit aluminum corrosion in a $1 \mathrm{M} \mathrm{HCl}$ solution, and it will also utilize a quantum chemical study to find out the active constituents of $P$. amarus that are responsible for corrosion inhibition.

\section{Materials and methods}

An aluminum sheet was obtained from the department of metallurgy at Ahmadu Bello University. Analar grade concentrated hydrochloric acid was purchased from Sigma Aldrich Chemical company, and double distilled water was used for the preparation of the test solution (i.e., $1 \mathrm{M} \mathrm{HCl}$ ). Samples of P. amarus leaves were obtained from the Ahmadu Bello University Botanical garden. The leaves were dried, grounded to powdered form and soaked in ethanol. Cold extraction was carried out, in order to obtain the ethanol soluble extract. The obtained extract was used to prepare an EEPA stock solution, from where 0.1, 0.2, 0.3, 0.4 and $0.5 \mathrm{~g} / \mathrm{L}$ concentrations were produced through serial dilution.

\section{Weight loss experiment}

Weight loss experiment was carried out by immersing a $5 \mathrm{x} 4 \mathrm{~cm}$ aluminum coupon in the respective test solution $(1 \mathrm{M} \mathrm{HCl}$, and $0.1,0.2,0.3,0.4$ and 0.5 $\mathrm{g} / \mathrm{L}$ of EEPA in $1 \mathrm{M} \mathrm{HCl}$, respectively) contained in a $250 \mathrm{~mL}$ beaker. It was ensured in all cases that the test solution sufficiently covered the metal. After every 24 hours, each coupon was withdrawn from the solution, washed in distilled water, dried and weighed. The experiments were repeated until 168 hours of immersion. Values of weight loss obtained after every 24 hours of immersion were recorded. From weight loss data, EEPA inhibition efficiency was calculated using equation (1):

$$
\% I E=\frac{\text { weight logs }}{\text { imitial weight }} \times \frac{100}{1}
$$

The degree of surface coverage was obtained by dividing the inhibition efficiency by 100 , while the aluminum corrosion rate $(\mathrm{CR})$ was measured using equation (2):

$$
C R\left(\mathrm{gcm}^{-2} h^{-1}\right)=\frac{\text { waight loss }}{\text { Area of the metal coupon } \times \text { period of immersion }}
$$

\section{Polarization study}

Linear polarization resistance (LP) measurements were carried out using a potentiostat (model AuT71791 and PGSTAT 30). The potential range of -1000 to $2000 \mathrm{mV}$, and a scan rate of $0.33 \mathrm{mV} / \mathrm{s}$ at $303 \mathrm{~K}$ were used. Each test was run in triplicate. All measurements were done in an autolab frequency response analyzer couple to a potentiostat, connected to a computer system. The working 
electrode was aluminum with an area of $1 \mathrm{~cm}^{2}$, while the counter electrode was a platinum electrode in a glass corrosion cell kit. The reference electrode was a $\mathrm{Ag} / \mathrm{Ag}$ system, and the experiment was carried out with the working electrode immersed in $1 \mathrm{M} \mathrm{HCl}$ under static conditions.

For PDP measurements, the inhibitor corrosion rate was calculated through corrosion current density, $1_{\text {corr, }}$, which was obtained by extrapolating the linear Tafel segments of the anodic and cathodic curves. Also, the inhibition efficiency (1\%) was calculated using equation (3) [12].

$$
I \%=\frac{i Q_{\text {vrr }}-i_{\text {Corr }}}{i i_{\text {Orr }}} \times \frac{100}{1}
$$

However, the over potential and current data were plotted on a linear scale to get LPR plots, and the plots slope in the vicinity of the corrosion potential gave the polarization resistance $\left(R_{p}\right)$. From the measured $R_{p}$ values, the inhibition efficiency (I \%) was calculated using the following equation [12]:

$$
I \%=\frac{R_{p(\ln n)}-R_{p}}{\left.R_{p(i n}\right)} \times \frac{100}{1}
$$

where $\mathrm{Rp}$ and $\mathrm{R}_{\mathrm{p}(\mathrm{inh})}$ are the uninhibited and inhibited polarization resistance, respectively.

\section{Quantum chemical calculations}

All chemical structures were drawn using the Chem draw package in the ChemBio2015 Cambridge software. Geometry optimization was performed with Hyperchem release 10 software, which was also used to calculate the compounds molecular energies using PM3 Hamiltonian. HOMO and LUMO diagrams were developed using the Chem 3D programme in the package of ChemBio2015 Cambridge software. All calculations were carried out at molecules gas phase state.

\section{Results and discussion Weight loss}

Aluminum weight loss, taken after every 24 hours immersion in the test solution, was used to develop weight loss variation graphs with time, and to estimate the relative values of aluminum corrosion rate. Fig. 1 shows weight loss variation plots with time for aluminum corrosion in a $1 \mathrm{M} \mathrm{HCl}$ solution containing various concentrations of EEPA at $303 \mathrm{~K}$. Graphs obtained at 313, 323 and $333 \mathrm{~K}$ are not shown, but the corrosion rates at $303 \mathrm{~K}$ and the temperatures are presented in Table 1. Geenerally, aluminum weight loss was found to increase with a larger period of contact, and with higher temperatures. The higher was EEPA addition, the lower was aluminum weight loss in $1 \mathrm{M} \mathrm{HCl}$. An increase in weight loss corresponded to an increase in corrosion rate, and vice versa. Therefore, EEPA decreased the aluminum corrosion rate in $1 \mathrm{M} \mathrm{HCl}$, which indicates that it worked as a corrosion inhibitor for that metal. EEPA inhibition efficiency 
increased with higher concentrations, but decreased with a rise in temperature, as shown in Table 1. It is an established fact that, from the pattern of inhibition efficiency variation with temperature, the adsorption mechanism can be proposed.

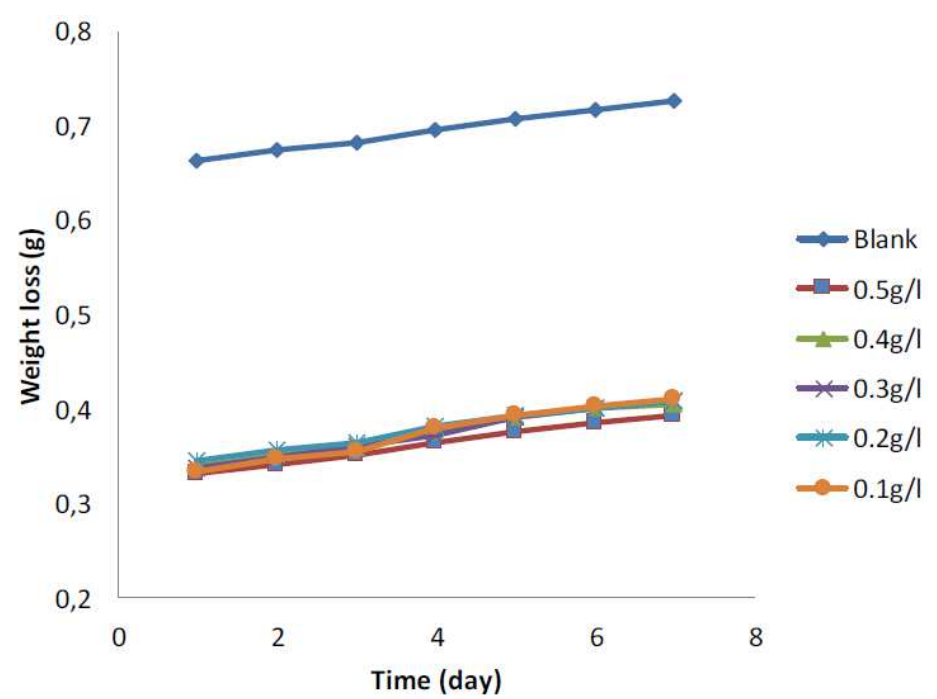

Figure 1. Variation of weight loss with time for aluminum corrosion in $0.1 \mathrm{M} \mathrm{HCl}$ containing various EEPA concentrations.

Table 1. Corrosion rate of aluminum in $\mathrm{HCl}$ solutions, and EEPA inhibition efficiency.

\begin{tabular}{|c|c|c|c|c|c|c|c|c|}
\hline & \multicolumn{4}{|c|}{$\mathbf{C R}\left(\mathbf{g} / \mathbf{h} / \mathbf{c m}^{2}\right)$} & \multicolumn{4}{c|}{$\mathbf{I \%}$} \\
\hline $\mathbf{C}(\mathbf{g} / \mathbf{L})$ & $\mathbf{3 0 3} \mathbf{~ K}$ & $\mathbf{3 1 3 ~ K}$ & $\mathbf{3 2 3} \mathbf{~ K}$ & $\mathbf{3 3 3} \mathbf{~ K}$ & $\mathbf{3 0 3} \mathbf{~ K}$ & $\mathbf{3 1 3} \mathbf{K}$ & $\mathbf{3 2 3} \mathbf{~ K}$ & $\mathbf{3 3 3} \mathbf{~ K}$ \\
\hline Blank & 0.00355 & 0.005206 & 0.010417 & 0.016861 & & & & \\
\hline 0.1 & 0.001539 & 0.002722 & 0.007233 & 0.012433 & 56.65 & 47.71 & 30.56 & 26.26 \\
\hline 0.2 & 0.001256 & 0.002489 & 0.006672 & 0.011222 & 64.63 & 52.19 & 35.95 & 33.44 \\
\hline 0.3 & 0.0012 & 0.002367 & 0.006544 & 0.010867 & 66.20 & 54.54 & 37.17 & 35.55 \\
\hline 0.4 & 0.001106 & 0.002383 & 0.006356 & 0.010633 & 68.86 & 54.22 & 38.99 & 36.94 \\
\hline 0.5 & 0.001094 & 0.002111 & 0.006033 & 0.010044 & 69.17 & 59.45 & 42.08 & 40.43 \\
\hline
\end{tabular}

Decreased inhibition efficiency with increasing temperatures points towards a physisorption mechanism, while an increased inhibition efficiency with higher temperatures defines a chemisorption mechanism. Therefore, EEPA adsorption onto the aluminum surface favours physical adsorption mechanism [13].

\section{Polarization study}

Data obtained from linear polarization (LPR) and potentiodynamic polarization (PDP) are presented in Table 2. Under LPR study, EEPA inhibition efficiency (IE) was also found to increase with higher concentrations, and ranged from 65.00 to $93.93 \%$, which is higher than the range of 56.65 to $69.17 \%$, obtained from weight loss measurements. Therefore, EEPA instantaneous inhibition potential is better than its average inhibition potential. The IE obtained for various EEPA concentrations from PDP measurements ranged from 51.38 to $79.96 \%$. This range also reveals that, for similar extract concentrations, the inhibition efficiencies obtained from PDP measurements are relatively higher 
than those obtained from weight loss measurements, but lower than those obtained from LPR measurements.

Table 2. Polarization data and inhibition efficiencies of various EEPA concentrations for $\mathrm{Al}$ corrosion in a $\mathrm{HCl}$ solution.

\begin{tabular}{|c|c|c|c|c|c|c|c|c|}
\hline \multirow{2}{*}{$\begin{array}{c}\mathbf{C} \\
(\mathbf{g} / \mathbf{L})\end{array}$} & \multicolumn{9}{|c|}{ PDP } & \multicolumn{2}{c|}{ LPR } \\
\cline { 2 - 9 } & $\beta_{\mathbf{a}}$ & $\beta_{\mathbf{b}}$ & $\begin{array}{c}\mathbf{E} \text { corr } \\
(\mathbf{V})\end{array}$ & $\begin{array}{c}\mathbf{I} \text { Corr } \\
(\mathbf{A})\end{array}$ & $\begin{array}{c}\mathbf{C R} \\
(\mathbf{m m} / \mathbf{y})\end{array}$ & $\boldsymbol{\%} \mathbf{I}$ & $\begin{array}{c}\mathbf{R}_{\mathbf{p}} \\
(\mathbf{\Omega})\end{array}$ & $\mathbf{I \%}$ \\
\hline Blank & 0.16516 & 0.076753 & -0.92637 & 0.000494 & 5.3597 & & 46.087 & \\
\hline 0.1 & 0.6669 & 0.081721 & -1.2171 & 0.000240 & 2.6058 & 51.38 & 131.69 & 65.00 \\
\hline 0.2 & 0.38349 & 0.68213 & -1.1110 & -1.109500 & 2.0371 & 61.99 & 568.03 & 91.89 \\
\hline 0.3 & 0.10458 & 0.084662 & -1.2103 & 0.000151 & 1.6397 & 69.41 & 134.51 & 65.74 \\
\hline 0.4 & 1.2355 & 0.037523 & -1.2155 & 0.000132 & 1.4333 & 73.26 & 119.77 & 61.52 \\
\hline 0.5 & -0.19327 & 0.091313 & -1.2551 & 0.000099 & 1.0741 & 79.96 & 759.63 & 93.93 \\
\hline
\end{tabular}

The PDP plots for various EEPA concentrations are presented in Fig. 2. In the inhibitor presence, the cathodic and anodic Tafel slopes are more or less equal, suggesting that EEPA acted as a mixed type inhibitor. In the plots, the transition from the active zone to the passivating zone, as the corrosion potential increases to the passivation potential $\left(\mathrm{E}_{\mathrm{pp}}\right)$, proves the formation of a passivating film.

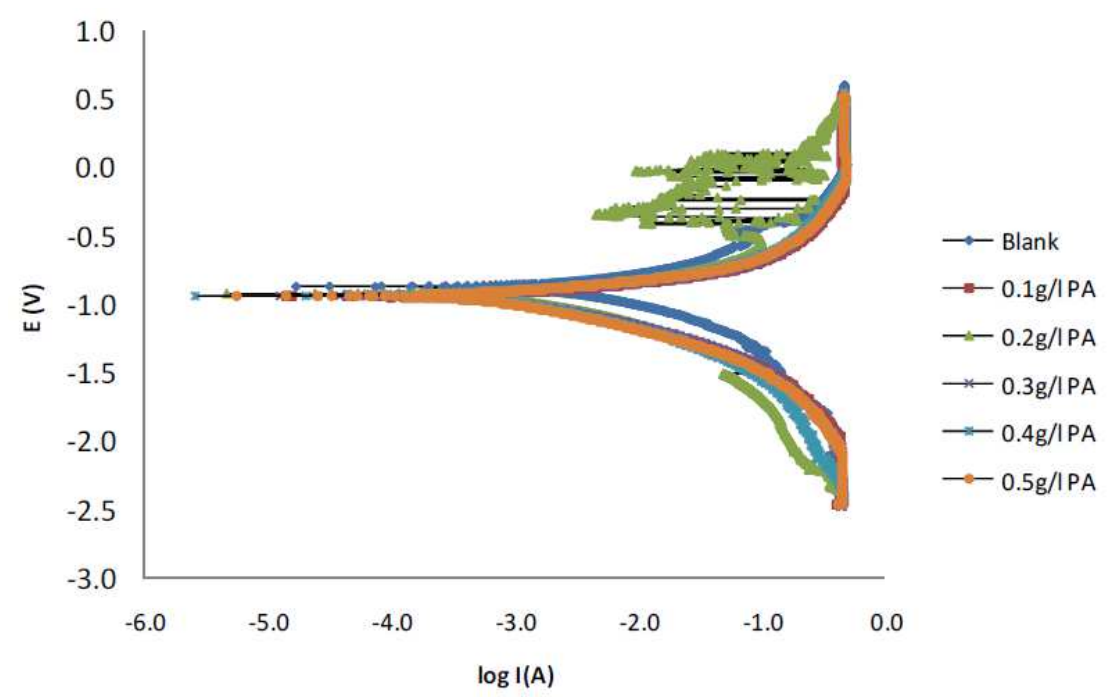

Figure 2. Potentiodynamic plots for aluminum corrosion in $1 \mathrm{M} \mathrm{HCl}$ containing various EEPA concentrations.

Mixed type inhibitors are generally known as corrosion inhibitors that form a protective film, which may be a precipitate that blocks the anode and cathode corrosion active sites, in order to protect the metal against further corrosion attack [14]. However, it is generally believed that, when the difference between the blank corrosion potential and that of the system containing the inhibitor is above $85 \mathrm{mV}$, then, the inhibitor can be classified as cathodic and anodic (Eddy et al., 2015). In this study, the differences for $0.1,0.2,0.3,0.4$ and $0.5 \mathrm{~g} / \mathrm{L}$ of EEPA were 291, 185, 284, 290 and $329 \mathrm{mV}$, respectively. Therefore, in addition to EEPA being a mixed type inhibitor, the cathodic behaviour dominantly contributes to its inhibitory behaviour. 


\section{Effect of temperature}

The Arrhenius equation is most suitable for estimating the minimum energy requirements for aluminum corrosion and its inhibition in $\mathrm{HCl}$ solutions. The model relates the corrosion rate to the activation energy, according to equation (5) [15],

$$
C R=\operatorname{Aexp}\left(\frac{-E_{\pi}}{R T}\right)
$$

where $\mathrm{CR}$ is the corrosion rate, $\mathrm{A}$ is the Arrhenius or pre-exponential factor, $\mathrm{E}_{\mathrm{a}}$ is the activation energy, $\mathrm{R}$ is the gas constant and $\mathrm{T}$ is the temperature. Equation (5) was applied by taking the natural logarithm of both sides to the obtained equation (6),

$$
\ln (C R)=\ln (A)-\frac{E_{a}}{k T}
$$

Since equation (6) is a linear model, a plot of $\ln (\mathrm{CR})$ versus $1 / \mathrm{T}$ was found to give a straight line, of which slope and intercept are $E_{a} / R$ and $\ln (\mathrm{A})$, respectively. This plot is shown in Fig. 3, and the various parameters deduced from the plots are recorded in Table $3 . \mathrm{R}^{2}$ values calculated from the plots were very close to unity, confirming a high degree of linearity, and the application of the Arrhenius model to the present data. From the results presented in Table 3, the activation energy for the blank was $44.62 \mathrm{~J} / \mathrm{mol}$. In the presence of various EEPA concentrations, the activation energy, which ranged from 60.23 to $64.03 \mathrm{~J} / \mathrm{mol}$, progressively increased with higher concentrations, indicating that the adsorption becomes more thermodynamically stable with increasing inhibitor concentrations.

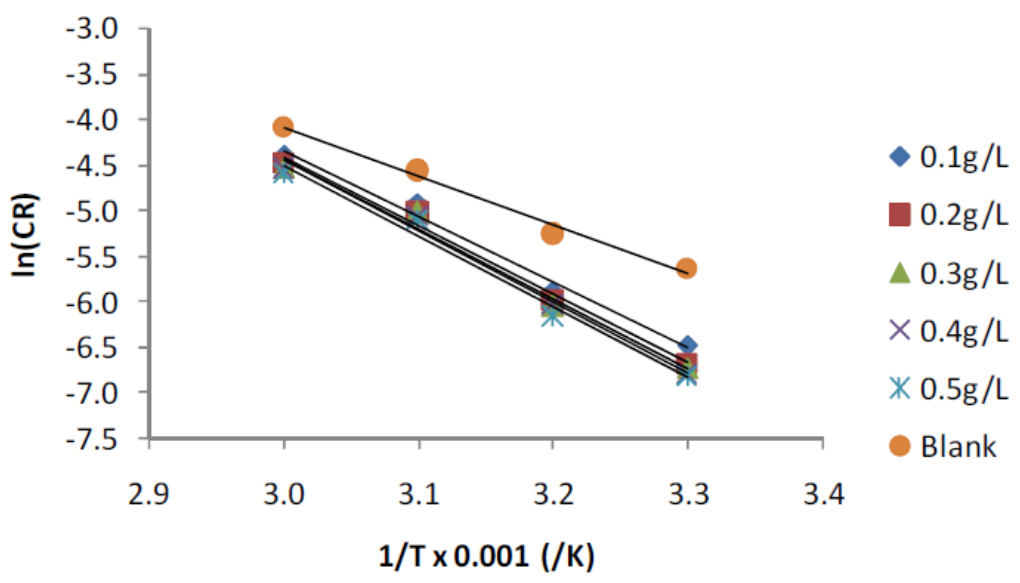

Figure 3. Arrhenius plot for aluminum corrosion in $1 \mathrm{M} \mathrm{HCl}$ containing various EEPA concentrations.

Generally, activation energy below $80 \mathrm{~kJ} / \mathrm{mol}$ points towards a physical adsorption mechanism, while that above $80 \mathrm{~kJ} / \mathrm{mol}$ is associated to a chemisorption mechanism [16]. Therefore, this indicates that EEPA adsorption onto the aluminum surface operates through the mechanism of physical adsorption. Table 3 also reveals that the Arrhenius or pre-exponential constant 
ranged from 17.39 to 18.58 , as against the value of 12.02 , recorded for the blank. Although the significance of the constant is not well known, an equilibration between the Arrhenius and the transition state equations reveals that it is associated with entropy.

Table 3. Arrhenius and transition state adsorption parameters for aluminum corrosion in $1 \mathrm{M} \mathrm{HCl}$ containing various EEPA concentrations.

\begin{tabular}{|c|c|c|c|c|c|c|c|c|}
\hline \multirow{2}{*}{$\begin{array}{c}\mathbf{C} \\
(\mathbf{g} / \mathbf{L})\end{array}$} & \multicolumn{2}{|c|}{ Arrhenius parameters } & \multicolumn{5}{|c|}{ Transition state parameters } \\
\cline { 2 - 9 } & $\begin{array}{c}\mathbf{L n} \\
(\mathbf{A})\end{array}$ & $\begin{array}{c}\mathbf{E}_{\mathbf{a}} \\
(\mathbf{J} / \mathbf{m o l})\end{array}$ & $\mathbf{R}^{2}$ & slope & intercept & $\begin{array}{c}\Delta S_{\text {ads }}^{0} \\
(\mathbf{m o l})\end{array}$ & $\begin{array}{c}\Delta H_{\text {ads }}^{0} \\
\mathbf{G / m o l})\end{array}$ & $\mathbf{R}^{2}$ \\
\hline Blank & 12.02 & 44.62 & 0.988 & 5.053 & 5.209 & -41.33 & -42.01 & 0.987 \\
\hline 0.1 & 17.39 & 60.23 & 0.986 & 6.93 & 10.64 & 3.82 & -57.62 & 0.985 \\
\hline 0.2 & 18.25 & 62.81 & 0.987 & 7.241 & 11.5 & 10.97 & -60.20 & 0.986 \\
\hline 0.3 & 18.44 & 63.41 & 0.985 & 7.312 & 11.69 & 12.55 & -60.79 & 0.984 \\
\hline 0.4 & 18.86 & 64.66 & 0.987 & 7.456 & 12.11 & 16.05 & -61.99 & 0.986 \\
\hline 0.5 & 18.58 & 64.03 & 0.983 & 7.386 & 11.83 & 13.72 & -61.41 & 0.982 \\
\hline
\end{tabular}

\section{Thermodynamic/adsorption study}

In the adsorption process, thermodynamic parameters of interest are entropy of adsorption, enthalpy of adsorption and standard free energy of adsorption. The transition state equation was used to estimate the entropy and enthalpy of EEPA adsorption onto the aluminum surface. The logarithmic form of the transition state equation, which relates the corrosion rate to temperature, can be expressed according to equation (7) [17],

$$
\ln \left(\frac{C R}{T}\right)=\ln \left(\frac{\pi}{N h}\right)+\left(\frac{\Delta S_{R d S}^{*}}{R}\right)-\frac{\Delta H_{\sigma d S}^{*}}{R T}
$$

where $\mathrm{N}$ is the Avogadro's number, $\mathrm{h}$ is the Planck constant, $\Delta S_{\text {ads }}^{\mathrm{x}}$ is the standard change in entropy and $\Delta H_{a d s}^{8}$ is the standard enthalpy change. In accordance with the mathematical implication of equation (7), values plotting of $\ln \left(\frac{C R}{T}\right)$ against $1 / \mathrm{T}$ (Fig. 4) gave straight lines with an excellent (approximating $100 \%$ ) degree of linearity.

Values of standard changes in entropy and enthalpy calculated from the plots intercepts and slopes are recorded in Table 3. The changes in entropy for the blank were $-41.33 \mathrm{~J} / \mathrm{mol}$, but in the presence of various EEPA concentrations, they ranged from 3.82 to $13.72 \mathrm{~J} / \mathrm{mol}$. Although changes in enthalpy ranged from -57.62 to $-61.99 \mathrm{~J} / \mathrm{mol}$ in the presence of various EEPA concentrations, it was $42.01 \mathrm{~J} / \mathrm{mol}$ for the blank. Positive values of entropy change suggest disorderliness, while negative values of enthalpy change indicate that the reaction was exothermic. However, a spontaneous adsorption will be defined when $\Delta S_{\text {ads }}^{8}$ is positive and $\Delta H_{a d s}^{*}$ is negative, or when $\Delta H_{a d s}^{*}<T \Delta S_{a d s}^{*}$. Within the confinement of the temperature range considered in this work, there is no doubt that the calculated values of changes in entropy and enthalpy will favour spontaneous EEPA adsorption onto the aluminum surface. Low values obtained 
for both thermodynamic parameters are consistent with the physical adsorption mechanism.

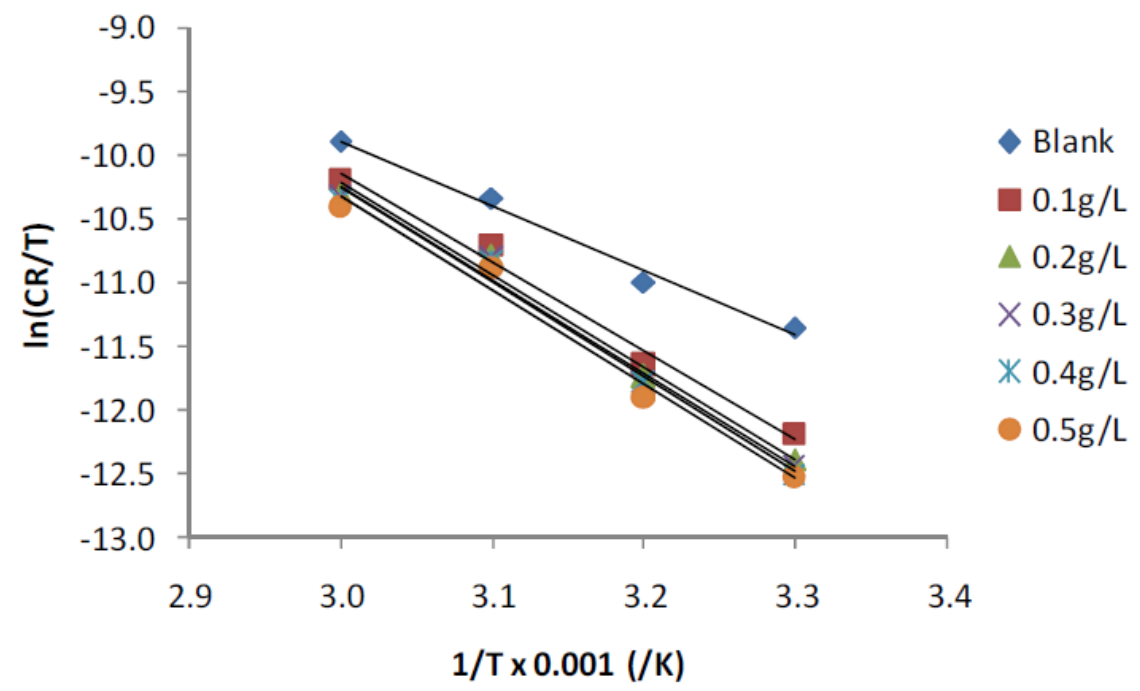

Figure 4. Transition state plot for aluminum corrosion in a $\mathrm{HCl}$ solution containing various EEPA concentrations.

In corrosion inhibition, adsorption is the initial mechanism for any inhibition process. Although there are two basic types of adsorption, differences exist between the adsorption characteristics of different inhibitors. The response of a given inhibitor to an established adsorption model provides information on the adsorption mode, and on the adsorption characteristies. In search for the best fitted adsorption isotherm for the studied inhibitor, different adsorption isotherms were tested, and the tests indicated that the best fitted adsorption isotherms are Langmuir and Freundlich ones. The Langmuir adsorption isotherm can be expressed as follows [18]:

$$
\ln \left(\frac{c}{\theta}\right)=\ln C-\ln b_{a d s}
$$

where $\mathrm{C}$ is the EEPA concentration in the bulk electrolyte, $\theta$ is the degree of EEPA surface coverage and $b_{\text {ads }}$ is the equilibrium constant of adsorption. In Fig. 5, the Langmuir isotherm for EEPA adsorption onto an aluminum surface is shown, while Table 4 contains adsorption parameters values deduced from the isotherms. The data fit to the Langmuir adsorption model are sustained by an excellent degree of linearity $\left(\mathrm{R}^{2}\right.$ ranged from 0.996 to 0.998). Values of the adsorption equilibrium constant were found to decrease with higher temperatures, which indicates that the strength of adsorption decreases with temperature, which is typical of a physisorption mechanism. However, slope values deviated from the ideal value of unity, and ranged from 0.748 to 0.880 . The basic assumptions of the Langmuir equation include the absence of interaction between the adsorbed molecules, and the homogeneity of all adsorption sites, which translates into the independency of the free energy of adsorption onto the surface site, and on the surface coverage. 


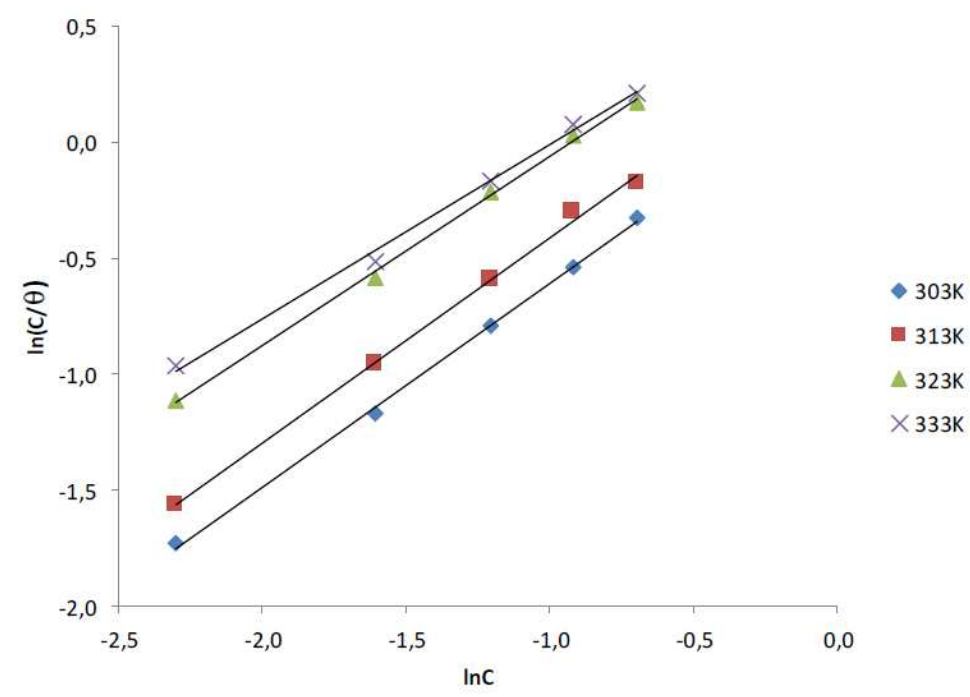

Figure 5. Langmuir isotherm for EEPA adsorption onto the aluminum surface.

Table 4. Langmuir and Freundlich parameters for EEPA adsorption onto the aluminum surface.

\begin{tabular}{|c|c|c|c|c|c|c|c|c|}
\hline \multirow[b]{2}{*}{$\mathbf{T}(\mathbf{K})$} & \multicolumn{4}{|c|}{ Langmuir } & \multicolumn{4}{|c|}{ Freundlich } \\
\hline & Slope & lnbads & $\begin{array}{c}\Delta G_{a d s}^{0} \\
\text { ( } / \mathrm{mol})\end{array}$ & $\mathbf{R}^{2}$ & $\mathbf{n}$ & Inbads & $\begin{array}{c}\Delta G_{a d s}^{0} \\
\text { O/mol })\end{array}$ & $\mathbf{R}^{2}$ \\
\hline $303 \mathrm{~K}$ & 0.875 & -0.264 & -9.45 & 0.998 & 0.125 & 0.264 & -10.78 & 0.945 \\
\hline $313 \mathrm{~K}$ & 0.880 & -0.464 & -8.95 & 0.998 & 0.125 & 0.464 & -11.29 & 0.911 \\
\hline $323 \mathrm{~K}$ & 0.815 & -0.753 & -8.22 & 0.998 & 0.200 & 0.753 & -12.0 & 0.971 \\
\hline $333 \mathrm{~K}$ & 0.748 & -0.735 & -8.27 & 0.996 & 0.250 & 0.735 & -11.97 & 0.967 \\
\hline
\end{tabular}

The non unity slope values obtained in this work suggest that these conditions are not met by EEPA adsorption onto the aluminum surface. The existence of interaction between adsorbed molecules, as indicated by the non unity slope values, may be due to lateral interaction existing in the molecules, when they get closer to each other. Therefore, there may be sites with different free energies of adsorption.

The assumptions establishing the Freundlich adsorption model can be written as [19]:

$$
\ln \theta=\ln b_{a d z}+\frac{1}{n} \ln C
$$

where $\theta$ is the degree of surface coverage, $b_{\text {ads }}$ is the adsorption equillibrium constant, and $\mathrm{C}$ and $\mathrm{n}$ are Freundlich constants; $\mathrm{b}_{\mathrm{ads}}$ is related to the adsorption capacity. The higher is the adsorption capacity, the higher is the value of $b_{\text {ads. }}$. On the other hand, $1 / \mathrm{n}$ is a measure of the intensity of adsorption. The higher is the value of $1 / n$, the more favourable is the adsorption. Generally, $n<1$ and $1 / n>1$. Fig. 6 shows the Freundlich isotherm for EEPA adsorption onto the aluminum surface. From the results of Freundlich adsorption parameters presented in Table 4 , it is evident that values of $1 / n$ and $b_{a d s}$ increase with higher temperatures, 
which suggests that the adsorption process becomes more stabilized as the temperature increases.

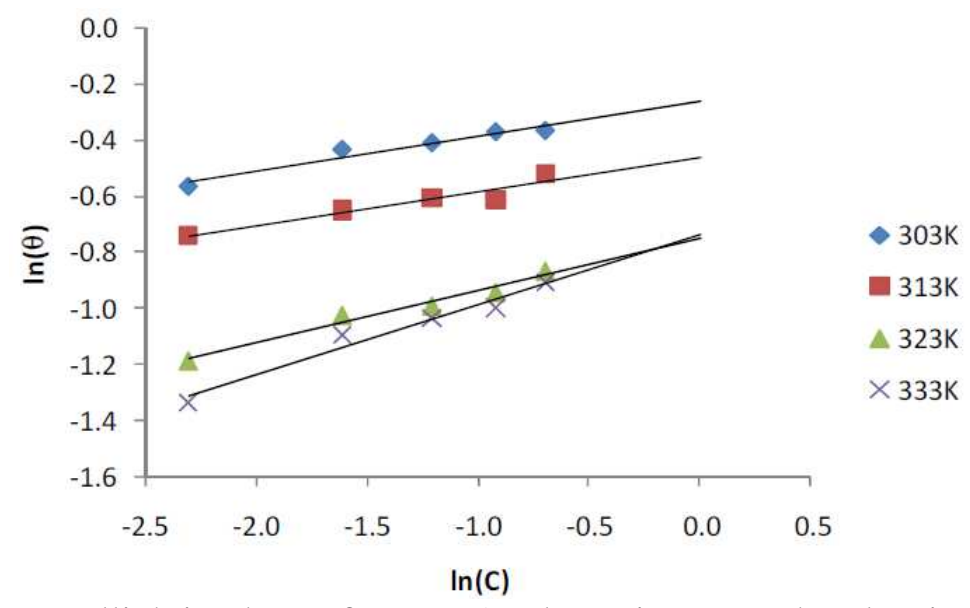

Figure 6. Freundlich isotherm for EEPA adsorption onto the aluminum surface.

The thermodynamic direction of a chemical reaction and the adsorption mechanism can be predicted through the sign and magnitude of standard free energy change. Generally, negative values of standard free energy change point towards spontaneous reactions, and values of standard free energy of adsorption upto $-20 \mathrm{~kJ} / \mathrm{mol}$ or less negative reflect physisorption mechanism. In this study, values of standard free energy change were calculated by transforming $b_{\text {ads }}$ values obtained from Langmuir and Freundlich isotherms through the following equation [20]:

$$
b_{a d s}=-\frac{1}{55.5} \exp \frac{\Delta G_{a d s}^{\circ}}{K T}
$$

Values of standard free energy of adsorption calculated from both options are recorded in Table 4. These values ranged from -9.45 to $-8.27 \mathrm{~J} / \mathrm{mol}$, and from -19.78 to $-11.97 \mathrm{~J} / \mathrm{mol}$, respectively. Therefore, EEPA adsorption is spontaneous, and favors the physical adsorption mechanism [21].

\section{Scanning electron microscopy (SEM)}

The SEM micrograph of the corroded aluminum surface drawn out from $\mathrm{HCl}$ test solution is presented in Fig. 7a. The micrograph obtained when $0.5 \mathrm{~g} / \mathrm{L}$ of EEPA was used as an inhibitor is also shown in Fig. 7b. It is evident from the micrographs that, in EEPA absence, the corrosion deeply penetrates the metal, whereas, in EEPA presence, the metal surface is covered by a protective layer. Therefore, EEPA formed a protective layer on the aluminum surface, preventing further corrosion attack.

Frequencies of IR adsorption deduced from EEPA FTIR spectra, and the aluminum corrosion product (when EEPA was used as an inhibitor), are presented in Table 5. Major functional groups associated to the various bonds in EEPA are $=\mathrm{C}-\mathrm{H}$ stretch, $\mathrm{C}-\mathrm{O}$ stretch, $\mathrm{N}-\mathrm{H}$ stretch, $\mathrm{C}=\mathrm{O}$ stretch and $\mathrm{OH}$ stretch. Interactions of the inhibitor with the metal surface remarkably shifted the $=\mathrm{C}-\mathrm{H}$ bend from 759 to $853 \mathrm{~cm}^{-1}$, the C-O stretch from 1050 to $1092 \mathrm{~cm}^{-1}$, another C-O stretch from 1210 to $1209 \mathrm{~cm}^{-1}$, C-C stretch from 1442 to $1443 \mathrm{~cm}^{-1}, \mathrm{~N}-\mathrm{H}$ bend 
from 1616 to $1614 \mathrm{~cm}^{-1}$ and $\mathrm{OH}$ stretch from 3416 to $3414 \mathrm{~cm}^{-1}$. However, $\mathrm{C}=\mathrm{O}$ stretch and $\mathrm{OH}$, which appeared on the EEPA spectrum at 1722 and $2935 \mathrm{~cm}^{-1}$, respectively, were missing. Therefore, EEPA was adsorbed onto the aluminum surface through these functional groups.

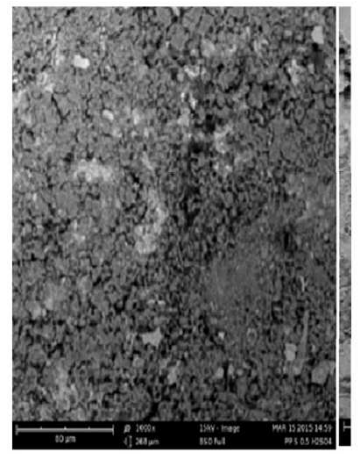

(a)

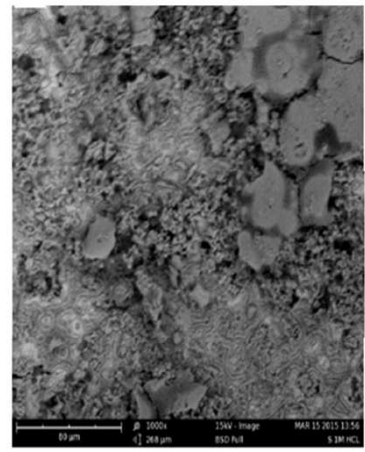

(b)

Figure 7. Scanning electron micrograph of aluminum corrosion product in the (a) absence and (b) presence of $0.5 \mathrm{~g} / \mathrm{L}$ of EEPA. Fourier transformed infra red (FTIR) spectroscopy.

Table 5. Peaks, frequencies and assignment of IR adsorption by EEPA, and aluminum corrosion product in EEPA presence.

\begin{tabular}{|c|c|c|r|r|c|}
\hline \multicolumn{3}{|c|}{ 0.5 g/L EEPA } & \multicolumn{2}{c|}{ Corrosion product + 0.5 g/L EEPA } \\
\hline $\begin{array}{c}\text { IR } \\
\text { frequency }\end{array}$ & Area & Assignment & $\begin{array}{c}\text { IR } \\
\text { frequency }\end{array}$ & Area & Assignment \\
\hline 759.01 & 55.71 & =C-H bend & 853.53 & 53.64 & $=$ C-H bend \\
\hline 1050.28 & 199.48 & C-O stretch & 1091.75 & 91.33 & C-O stretch \\
\hline 1210.37 & 94.66 & C-O stretch & 1209.41 & 49.57 & C-O stretch \\
\hline 1441.84 & 89.52 & C-C stretch (in ring) & 1442.8 & 98.72 & C-C stretch (in ring) \\
\hline 1616.40 & 71.77 & N-H bend & 1613.51 & 164.17 & N-H bend \\
\hline 1721.53 & 125.97 & C=O stretch & - & - & - \\
\hline 2934.79 & 790.05 & O-H stretch & - & - & - \\
\hline 3416.05 & 624.96 & O-H stretch & 3414.12 & 881.09 & O-H stretch \\
\hline
\end{tabular}

\section{EEPA active constituents and their adsorption properties}

EEPA major chemical constituents are phyllanthusin D, phyllanthin, hypophyllanthin, quercetin, amarin, 1,2,8-trimethyl-7-vinylnaphthalene, etc. [89]. The chemical structures of these compounds are shown in Fig. 8. As a rule, most organic corrosion inhibitors are compounds that have hetero atoms in the aromatic ring or long carbon chain. In addition, availability of the conjugated system, suitable functional groups and $\pi$-electrons are additional features that can effectively enhance the corrosion inhibition efficiencies of organic inhibitors [22]. A careful examination of the chemical strutures of EEPA's major constituents (i.e., Fig. 8) convincingly reveals that it has compounds that meet these conditions. Therefore, its good inhibition properties can be alligned to its chemical constituents. A classical inspection of the chemical strutures of these compounds can not, in any way, furnish information on the preferred compounds that are responsible for corrosion inhibition, or provide an order for their 
increasing inhibition efficiency. According to Eddy et al. [23], quantum chemical indices, such as the frontier molecular orbital energies, can be used to effectively sort the compounds by their inhibition efficiency in an increasing or decreasing order.

\section{Quantum chemical study}

Table 6 presents calculated values of EEPA molecular energies. The calculated energies include the frontier molecular energies, i.e., the energy of the highest occupied molecular orbital (Еномо), the energy of the lowest unoccupied molecular orbital ( $\left.\mathrm{E}_{\mathrm{LUMO}}\right)$, the energy gap $\left(\mathrm{E}_{\mathrm{L}-\mathrm{H}}\right.$ or $\left.\Delta \mathrm{E}\right)$, the molecules electronic energy $\left(E_{E l e c t}\right)$, the molecules binding energy $\left(E_{b}\right)$ and the core- core repulsion energy $\left(\mathrm{E}_{\mathrm{CCR}}\right)$.

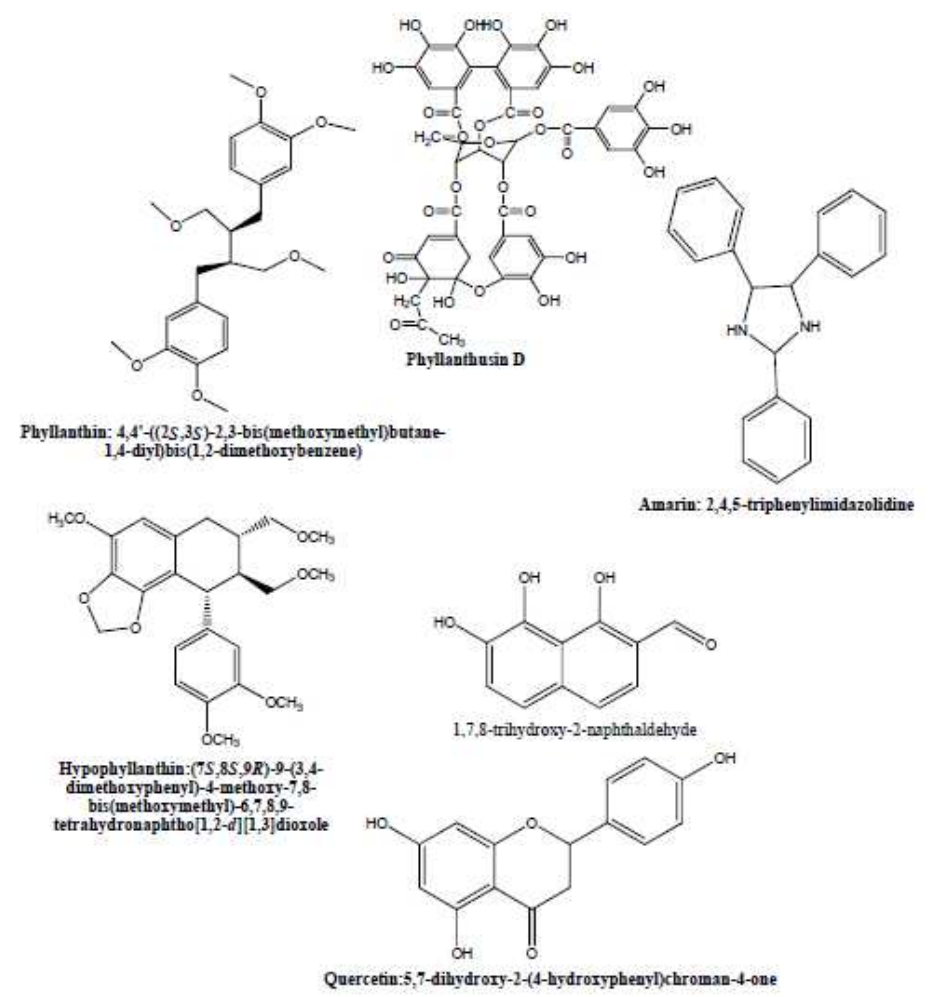

Figure 8. Chemical structures of EEPA's major components.

Table 6. Molecular energies of EEPA's chemical constituents.

\begin{tabular}{|l|c|c|c|r|r|r|}
\hline & $\begin{array}{c}\mathbf{E}_{\text {Hомо }} \\
(\mathbf{e V})\end{array}$ & $\begin{array}{c}\mathbf{E}_{\mathbf{L U M O}} \\
(\mathbf{e V})\end{array}$ & $\begin{array}{c}\Delta \mathbf{E} \\
(\mathbf{e V})\end{array}$ & $\begin{array}{c}\mathbf{E}_{\mathbf{b}} \\
(\mathbf{e V})\end{array}$ & $\begin{array}{c}\mathbf{E}_{\text {elect }} \\
(\mathbf{e V})\end{array}$ & $\begin{array}{c}\mathbf{E}_{\mathbf{C C R}} \\
(\mathbf{e V})\end{array}$ \\
\hline phyllanthusin D & -8.991 & -1.477 & 7.515 & -13185.71 & -182580.92 & 168887.19 \\
\hline phyllanthin & -8.713 & 0.388 & 9.101 & -277.24 & -47714.94 & 42574.78 \\
\hline hypophyllanthin & -8.912 & 0.380 & 9.292 & -271.33 & -49559.28 & 44187.35 \\
\hline quercetin & -9.615 & -0.634 & 8.981 & -156.38 & -22234.13 & 18797.03 \\
\hline amarin & -9.411 & 0.143 & 9.554 & -205.41 & -25771.90 & 22646.24 \\
\hline $\begin{array}{l}1,2,8-\text { trimethyl-7- } \\
\text { vinylnaphthalene }\end{array}$ & -8.684 & -0.935 & 7.750 & -112.90 & -2492.07 & 12143.42 \\
\hline
\end{tabular}

From the point of view of corrosion inhibition, EHOMO represents the tendency of a chemical species to donate electrons or charge, indicating that the higher is $\mathrm{E}_{\mathrm{HOMO}}$ value, the better is the expected inhibition efficiency [24]. On the other 
hand, ELUMo is an index that corresponds to the tendency of a chemical species to accept electrons or charge during a reaction; therefore, a better corrosion inhibitor should be characterized by low $E_{\text {LUMO }}$ values [25]. The differences between $\mathrm{E}_{\mathrm{LuMO}}$ and $\mathrm{E}_{\mathrm{HOMO}}$ define the energy gap of a molecule. Based on the energy gap, molecules may be classified as hard or soft. Soft molecules are more reactive than hard molecules, because they have a lower energy gap, indicating that the energy needed for an electron to move from HOMO to LUMO level will be minimal, compared to that of the hard molecules. The easier is an inhibitor transition from HOMO to LUMO level, the better is the expected efficiency. Therefore, soft molecules are expected to exhibit better inhibition efficiencies than hard molecules.

Based on $\mathrm{E}_{\mathrm{HOMO}}$ value, contributions of EEPA constituents to its inhibition efficiency for aluminum corrosion are expected to be consistent with the following order: 1,2,8-trimethyl-7-vinylnaphthalene > phyllanthin > hypophyllanthin $>$ phyllanthusin $\mathrm{D}>$ amarin $>$ quercetin. However, based on the ELUMo respective values, the expected order should be: phyllanthin $\mathrm{D}>1,2,8$ trimethyl-7-vinylnaphthalene $>$ quercetin $>$ amarin $>$ hypophyllanthin > phyllanthin, but based on the enery gap, which is described as the difference between ELUmo and EHOMO, the expected trend is: pyllanthusin > 1,2,8-trimethyl7-vinylnaphthalene $>$ quercetin $>$ phyllanthin $>$ hypophyllanthin $>$ amarin. The binding energy of a molecule represents the energy that is holding it together. This means the higher is the binding energy, the more difficult it would be for the molecule to go into reaction. Consequently, based on the $\mathrm{E}_{\mathrm{b}}$ of the molecules in EEPA, the relative contribution to corrosion inhibition should be: phyllanthusin D > phyllanthin > hypophyllanthin > amarin > quercetin > 1,2,8trimethyl-7-vinylnaphthalene. Similarly, the higher is the energy possessed by electrons, the better should be the expected inhibition efficiency. Consequently, the expected trend for the inhibition efficiency variation, based on the Eelectr is: phyllanthusin D > hypophyllanthin > phyllanthin > amarin > 1,2,8-trimethyl-7vinylnaphthalene $>$ quercetin. Finally, core-core repulsion energy is expected to increase with inhibition efficiency, and the expected trend is: phyllanthusin D > hypophyllanthin > phyllanthin $>$ amarin > quercetin > 1,2,8-trimethyl-7vinylnaphthalene.

From the above analysis, it is evident that phyllanthusin $\mathrm{D}$ is the major contributor to EEPA's corrosion inhibition potential, but this does not imply that the other constituents do not significantly contribute for it. It is necessary to state that, in a system such as EEPA, where there are different corrosion active components, the overall inhibition efficiency is a consequence of the synergistic adsorption of the various active components in the inhibitor. It is also interesting to state that all the molecular energies calculated for the various EEPA's constituents are within the range of the values expected for good corrosion inhibitors.

In Fig. 9, HOMO and LUMO diagrams of phyllanthusin D are shown. It is interesting to note that, while the positive and negatives lobes of the phyllanthusin D HOMO diagram are resting on the biphenyl-2,2',3,3',4,4'hexanol end of the molecule, those of LUMO are concentrated on the 5,5,6- 
trihydroxy-6-(2-oxopropyl)cyclohex-2-enone end of the molecule. This implies that biphenyl-2,2',3,3',4,4'-hexanol end, which has several hydroxyl bonds, will be the electron or charge donating site. The molecular orbital diagrams support the finding from FTIR results that hydroxyl and carboxyl groups are essential for the EEPA adsorption onto the molecule surface.

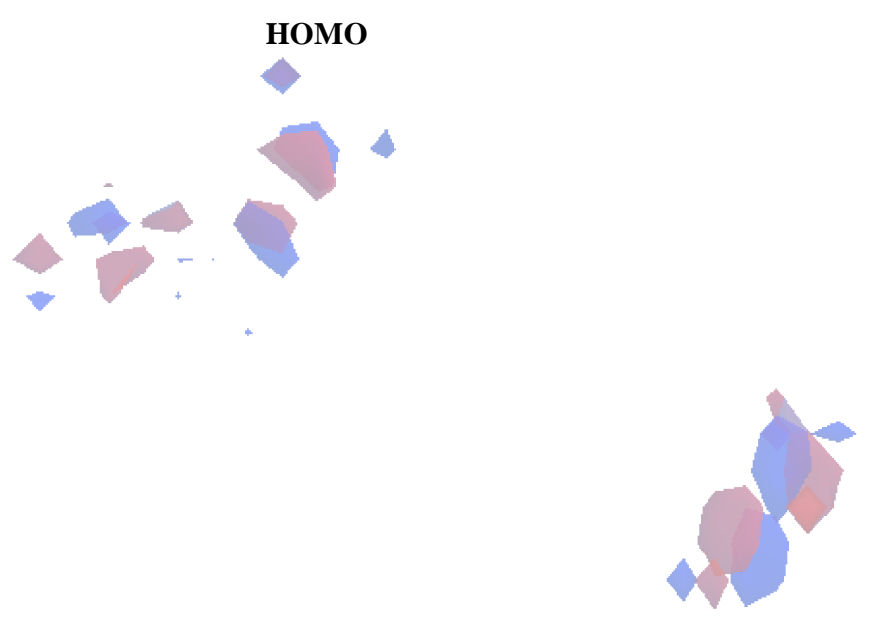

LUMO

Figure 9. HOMO and LUMO diagrams of phyllanthusin D.

\section{Conclusion}

The present study was aimed at investigating EEPA corrosion inhibition properties for aluminum in a $\mathrm{HCl}$ solution, and to examine the major components that are responsible for its inhibitive action. The study reveals that EEPA is a good adsorption inhibitor that is capable of inhibiting the aluminum corrosion in $1 \mathrm{M} \mathrm{HCl}$ to a large extent. However, the instantaneous inhibition potential of the extract is better than its average inhibition efficiency. EEPA acted as a mixed type corrosion inhibitor, blocking active corrosion sites of the metal surface through the formation of a protective film. The inhibitor adsorption mechanism is consistent with physisorption. The inhibitor adsorption onto the aluminum surface is spontaneous, and its characteristics excellently allign with the Langmuir and the Freundlich adsorption models.

\section{References}

1. Founda AS, Al-Sarawy AA, Sh-Ahmed F, et al. Corrosion inhibition of aluminum 6063 using some pharmaceutical compounds. Corros Sci. 2009;51:485-492.

2. Maayta AA, El Rawashdeh NAF. Inhibition of acidic corrosion of pure aluminium by some organic compounds. Corros Sci. 2004;46:1129-1140.

3. Eddy NO, Ibok UJ, Ameh PO, et al. Adsorption and quantum chemical studies on the inhibition of the corrosion of aluminum in $\mathrm{HCl}$ by Gloriosa superba (GS) gum. Chem Eng Comm. 2014;201:1360-1383.

4. Amitha Rani BE, Basu BBJ. Green inhibitors for corrosion protection of metals and alloys: An overview. Int J Corros. 2012:ID 380217. 
5. Bushweishaija J. Photochemicals as green corrosion inhibitors in various media. A review. Tanz J Sci. 2009;35:77-85.

6. Eddy NO. Ethanol extract of Phyllanthus amarus as a green inhibitor for the corrosion of mild steel in $\mathrm{H}_{2} \mathrm{SO}_{4}$. Port Electrochim Acta. 2009;27:579-589.

7. Okafor PC, Ikpi ME, Uwah IE, et al. Inhibitory action of phyllanthus amarus extracts on the corrosion of mild steel in acidic media. Corros Sci. 2008;50:23102317.

8. Sangeetha M, Rajendran S, Sathiyabama J, et al. Corrosion inhibition by aqueous extract of Phyllanthus amarus. Port Electrochim Acta. 2011;29:429-444.

9. Pasupathy A, Nirmala S, Abirami G, et al. Inhibitive action of Phyllanthus amarus extract on the corrosion of zinc in $0.5 \mathrm{~N} \mathrm{H}_{2} \mathrm{SO}_{4}$. Int J Sci Res Publ. 2014;4:1-3.

10. Sribharathy V, Rajendran S, Sathiyabama J. Inhibitory action of phyllanthus amarus extracts on the corrosion of mild steel in seawater. Chem Sci Trans. 2013;2:315-321.

11. Olusegun KA, Otaigbe JOE. Effect of Phyllanthus amarus extract on corrosion and kinetic of the corrosion process of aluminm in alkaline solution. Corros Sci. 2009;51:2790-2793.

12. Ameh PO, Eddy NO. Theoretical and experimental studies on the corrosion inhibition potentials of 3-nitrobenzoic acid for mild steel in $0.1 \mathrm{M} \mathrm{H}_{2} \mathrm{SO}_{4}$. Cogent Chem. 2016;2:1253904.

13. El ouariachi E, Bouyanzer A, Salghi R, et al. Inhibition of corrosion of mild steel in $1 \mathrm{M} \mathrm{HCl}$ by the essential oil or solvent extracts of Ptychotis verticuillata. Research Chem Interm. 2015;41:935-946.

14. Finsgar M, Jackson J. Application of corrosion inhibitor for steel in acidic media for the oil and gas industry: A review. Corros Sci. 2014;86:17-41.

15. Chaubey N, Singh VK, Quraishi MAS, et al. Corrosion inhibition of aluminum alloy in alkaline media by Neolamarkia cadamba bark extract as a green inhibitor. Int J Electrochem Sci. 2015;10:504-518.

16. Prasanna BM, Praveen BM, Hebbar N, et al. Inhibition study of mild steel corrosion in $1 \mathrm{M}$ hydrochloric acid solution by 2-chloro-3-formyl quinoline. Int $\mathbf{J}$ Ind Chem. 2016;7:9-19.

17. Singh A, Singh VK, Quraishi MA (2013) Inhibition of the corrosion of mild steel in HCl using Papali (Piper longum) fruit extract. Arab J Sci Eng. 2013;38(1), 85-97.

18. Wang HL, Fan H, Zhang J. Corrosion inhibition of mild steel in hydrochloric acid solution by a mercapto-triazole compound. Mater Chem Phys. 2003;72:655-661.

19. Khadom AA, Yaro AS, Kadhum AAH. Adsorption of benzotriazole for corrosion inhibition of zinc-copper alloy in HCl. J Chil Chem Soc. 2010;1:150-152.

20. Umoren SA, Banera MJ, Alonso-Garcia T, et al. Inhibition of mild steel corrosion in $\mathrm{HCl}$ solution using chitosan. Cellulose. 2013;20:2529-2545.

21. Orubite KO, Oforka NC. Inhibition of the corrosion of mild steel in hydrochloric acid solution by the extract of leaves of Nypa fruticans wurmbs. Mater Lett. 2004;58:1768- 1772.

22. Raghavendra N, Bhat I. Green approach to inhibition of corrosion of aluminum in $0.5 \mathrm{M} \mathrm{HCl}$ medium by tender arecanut seed extract: Insight from gravimetric and electrochemical studies. J Chem Intermed. 2016;42:6351.

23. Eddy NO, Momoh-Yahaya H, Oguzie EE. Theoretical and experimental studies on the corrosion inhibition potentials of some purines for aluminum in $0.1 \mathrm{M} \mathrm{HCl}$. J Adv Res. 2015;6:203-216. 
24. Eddy NO, Ita BI. Experimental and theoretical studies on the inhibition potentials of some derivatives of cyclopenta-1,3-diene. Int J Quantum Chem. 2011;111:34563473.

25. Eddy NO, Ita BI. Theoretical and experimental studies on the inhibition potentials of aromatic oxaldehydes for the corrosion of mild steel in $0.1 \mathrm{M} \mathrm{HCl}$. J Mol Model. 2011;17:633-647. 